\title{
29 Involvement of Insect Pests in Plant and Crop Stress
}

\author{
Stefano Speranza, Angelo Mazzaglia, \\ Antoine Harfouche, and Asghar Heydari
}

\section{CONTENTS}

29.1 Introduction

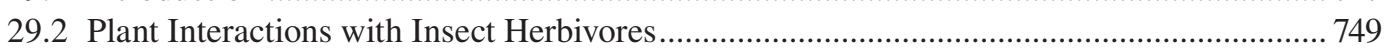

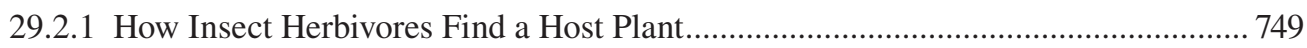

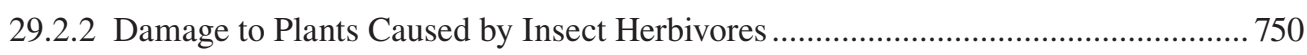

29.2.2.1 Herbivory in Aboveground and Belowground Plant Tissues..................... 750

29.2.2.2 Plant Compensation to Insect Herbivores Damage .................................. 751

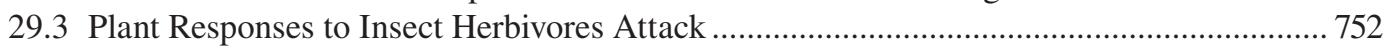

29.3.1 Early Events in Plant-Insect Interactions ........................................................... 753

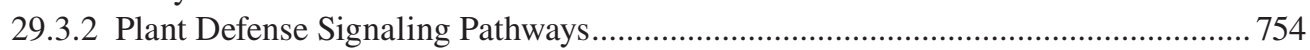

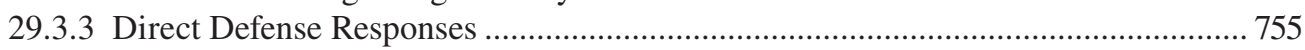

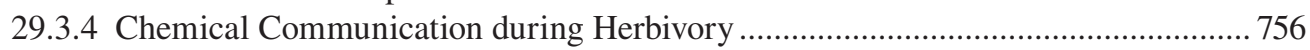

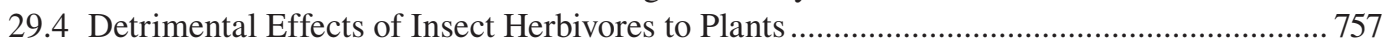

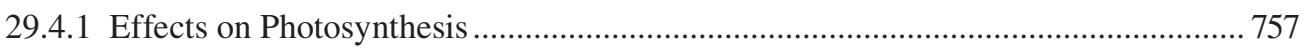

29.4.1.1 Direct Reduction of Photosynthetic Capacity........................................... 757

29.4.1.2 Indirect Reduction of Photosynthetic Capacity ........................................ 758

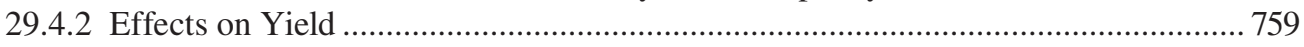

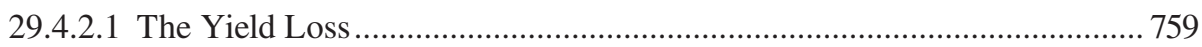

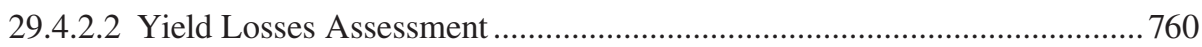

29.4.2.3 Economic Injury Level and Economic Threshold ....................................... 760

29.4.2.4 Damage in Natural and Agricultural Environments...................................760

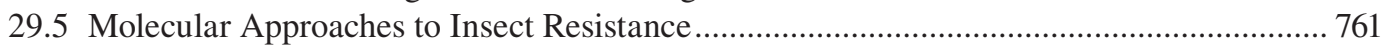

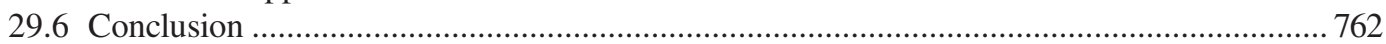

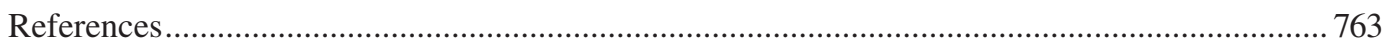

\subsection{INTRODUCTION}

Several stresses can be involved during the life of plants. One of the major stress is caused by tissue damage. Tissue damage in plants is most often associated with insect herbivore infestation. The insect uses the plant as a source of food but the plant tissue consists of dilute nutrients in a matrix of indigestible structural compounds, such as cellulose and lignin, and a variety of allelochemicals. The insect differs from other animals in that it lacks the capacity to synthesize sterols. The insect, in fact, must extract sterol together with several other essential nutrients (amino acids, carbohydrates, lipids, fatty acid, vitamins, trace element) from their food (Behmer and Nes, 2003). Optimal insect growth, survival, and fecundity require certain proteins: carbohydrate ratios, which may vary considerably among species and developmental stages (Schoonhoven et al., 2005). The food is not totally converted to insect biomass but follow the decrease line from food ingested to growth and 